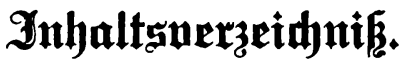

\author{
Eriter $\mathfrak{A} \mathfrak{b} \mathfrak{i}$ dyitt.

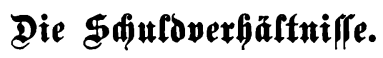

1. Schuldverhältniffe mit und ohne (Seldeşwerth

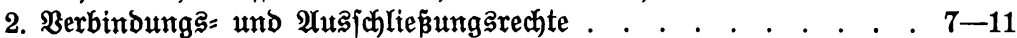

3. (Entftehung von Schuldverhältniffen burch Rechtsgefchäft. . . . 11-13

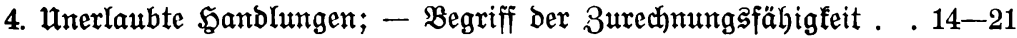

5. Sejebliche Begrenzung Der f(huldonerifhen Şaftung . . . . . . 21-26

6. Unvolfommene Rechtsperbinslichfeiten . . . . . . . . . . 26-30

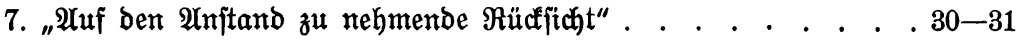

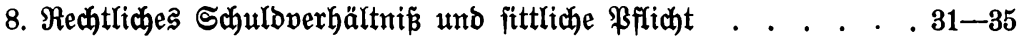

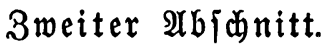

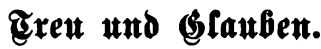

9. Die $\mathfrak{F r a g e f t e l l u n g}$. . . . . . . . . . . . . . . . . . . 36-39

10. Die Methode der \&b̈jung bez $\mathfrak{B r o b l e m}$. . . . . . . . . . . . 39-42

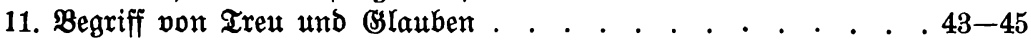

12. $\Re_{0}$ fitiv=rechtlid und objeftiv=richtig . . . . . . . . . . . 46-50

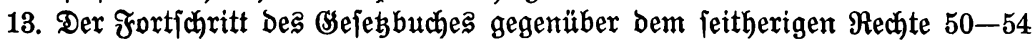

\section{Dritter $\mathfrak{A} \mathfrak{b} \mathfrak{C H}$ itt.}

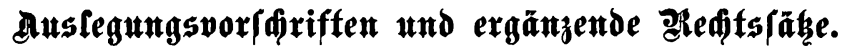

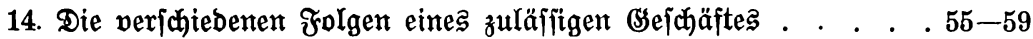

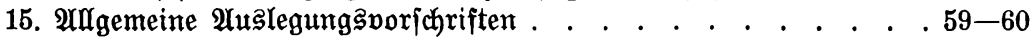

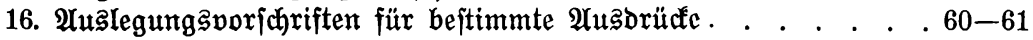

17. $\mathfrak{A} \mathfrak{u} \mathfrak{l}$ legung:

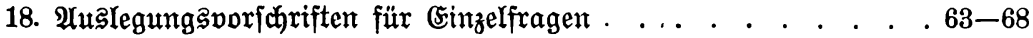

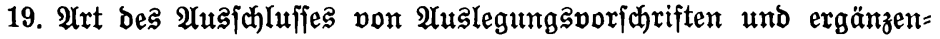
bem Rechte . . . . . . . . . . . . . . . . . . . 68-70

20. Bebeutung bes unterjutedes bei Rollifiton von Reichs Eandesrecht . . . . . . . . . . . . 70-72 
Geite

21. 3wingende Einzelfolgen nach Dem Rechte des Şejebbuches . . 72- Z4

22. $\mathfrak{A}$ usbrüdfliche $\mathfrak{B e r n e i m u n g}$ bes zmingenden Sharafters von Rechtsjäben . . . . . . . . . . . . . . . . . . 74- 76

23. "Эm Zmeifel". . . . . . . . . . . . . . . . . . . 76-79

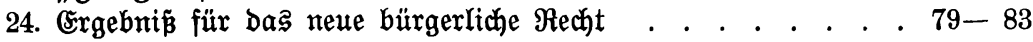

\section{Bierter 2 Abjunitt.}

\section{(Segenleitige \$̧erträge.}

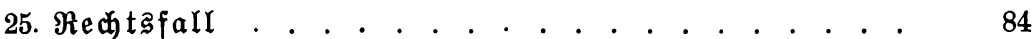

26. Segenjeitiger Bertrag und Schenfung unter einer $\mathfrak{A}$ uflage . . 84- 86

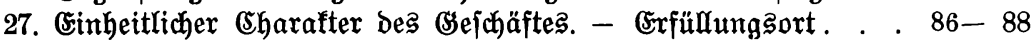

28. Clausula rebus sic stantibus . . . . . . . . . . . . . . S8-94

29. Einrebe bes nicht exfüllten Bertrages . . . . . . . . . . 95-101

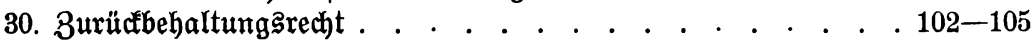

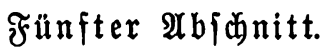

己̇umōglifłkeif ber Seiffung.

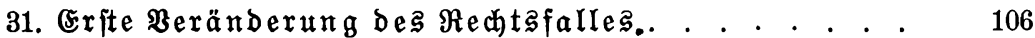

32. $\mathfrak{u} r \mathfrak{p r u ̈ n g l i c h e ~} \mathfrak{u n m o ̈ g l i c h f e i t . ~ . ~ . ~ . ~ . ~ . ~ . ~ . ~ . ~ . ~ . ~ . ~ . ~ . ~ . ~ . ~ . ~ 1 0 6 - 1 0 9 ~}$

33. Nachfolgende Unmöglichfeit, - Şrünbe ber Schabenszurechnung 109-119

34. Tabelle ber wahlmeifen Befugniffe dę (słläubigerz . . . . . 119-122

35. Bemeffung bes Schadenserjazes . . . . . . . . . . . . 122-129

36. Rüctrittarecht . . . . . . . . . . . . . . . . . . . 129-131

37. Rehre vom Eommodum . . . . . . . . . . . . . . . 131-133

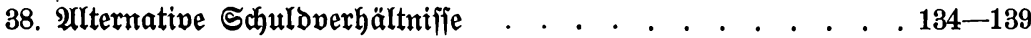

Sechfter $\mathfrak{A b}$ đ̆nitt.

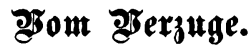

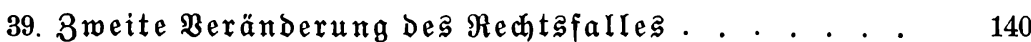

40. Rechte Beit ber Leiftung . . . . . . . . . . . . . . . 140-142

41. $\mathfrak{B}$ erzug bes jahuldenden $\mathfrak{B e r f a ̈ u f e r s ~ . ~ . ~ . ~ . ~ . ~ . ~ . ~ . ~ . ~ . ~ . ~ 1 4 2 - 1 4 6 ~}$

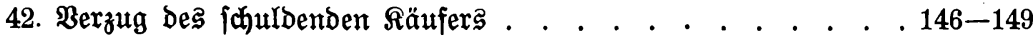

43. Beripätung Der Leijtung ohne Berzug bes Schuldners . . . . 149-151

44. Berzug dę \&läubigeræ . . . . . . . . . . . . . . . 151-154

Siebenter $\mathfrak{A b} \mathfrak{d}$ nitt.

ßłe/onders gearteter Seiftungsinfalt.

45. 3weiter Redtifall . . . . . . . . . . . . . 155-156

46. Bejtimmtheit ber \&eiftung . . . : . . . . . . . . . . 156-159 
Gette

47. Bertraggjtrafe . . . . . . . . . . . . . . . . . . . 159-163

48. Reugeld . . . . . . . . . . . . . . . . . . . . . 163-165

49. Berprechen ber Leijtung an einen Dritten . . . . . . . . 165-179

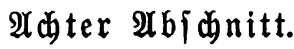

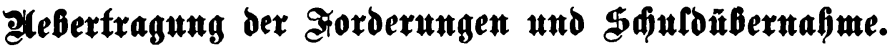

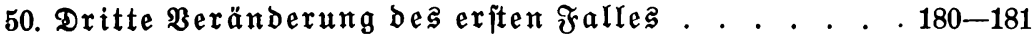

51. Sozialmixthichaftliche Bedentung ber Eeffion . . . . . . . . 181-188

52. Buläffitgfeit ber Uebertragung von Forburungen . . . . . . 188-193

53. Fibuziarifhe Eeffiton . . . . . . . . . . . . . . . . 193-197

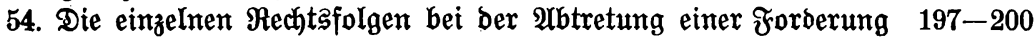

55. Uebertragung einer forberung traft Bsejege? . . . . . . . 200-206

56. Die $\mathfrak{u}$ ebernahme frembcr Squlden . .. . . . . . . . . . 206-213

\section{Neunter $\mathfrak{A} \mathfrak{b}\{\mathfrak{d}$ nitt.}

\section{Endigung von Forberungen tnd \$djulden.}

57. Bierte $\mathfrak{B}$ eränderung bes Rechtafalle? . . . . . . . 214

58. Die Cxfüllung von Forberungen . . . . . . . . . . . . . 214-221

59. Crxüulung an und burch Dritte . . . . . . . . . . . . 221-228

60. Leiftung an Exfüllungaftatt. . . . . . . . . . . . . . 229-233

61. Ginterlegung . . . . . . . . . . . . . . . . . . . 233-240

62. $\mathfrak{A} \mathfrak{u}$ frechmung . . . . . . . . . . . . . . . . . . . 240-245

3egnter $\mathfrak{A b j} \mathfrak{d}$ nitt.

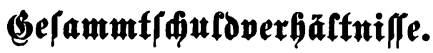

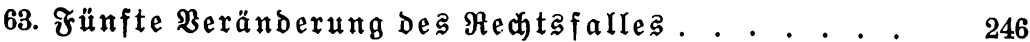

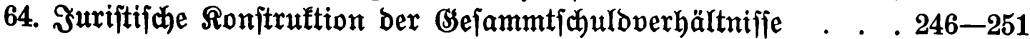

65. Entitehung von (sejammtiðhuldoverhältnifjen . . . . . . . 251-254

66. Endigungsgründe bei (Sejammtjhuldoverhältniffen . . . . . 254-262 